\title{
Endoscopic retrograde cholangiopancreatography for biliary system parasites
}

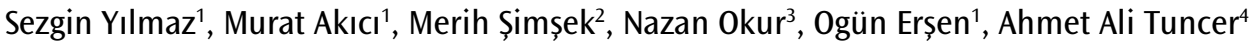

\begin{tabular}{|c|c|}
\hline \multirow[t]{4}{*}{ ABSTRACT } & $\begin{array}{l}\text { Objective: Endoscopic retrograde cholangiopancreatography may be useful in the diagnosis and management of } \\
\text { biliary system parasites. }\end{array}$ \\
\hline & $\begin{array}{l}\text { Material and Methods: Investigators retrospectively evaluated patients with biliary system parasites who underwent } \\
\text { endoscopic retrograde cholangiopancreatography procedures over an eight-year period. We collected data regard- } \\
\text { ing patient demographics, clinical features, and parasite type. We aimed to determine the utility of endoscopic } \\
\text { retrograde cholangiopancreatography as a diagnostic and therapeutic intervention in patients with biliary system } \\
\text { parasites. }\end{array}$ \\
\hline & $\begin{array}{l}\text { Results: We identified } 22 \text { patients with biliary system parasites from a total of } 3,450 \text { endoscopic retrograde cholan- } \\
\text { giopancreatography procedures performed during an eight-year period. Parasite types included Echinococcus granu- } \\
\text { losus }(n=19) \text {, Fasciola hepatica }(n=2) \text {, and Ascaris lumbricoides }(n=1) \text {. Fifteen patients with liver hydatid cysts under- } \\
\text { went endoscopic retrograde cholangiopancreatography prior to surgery due to obstructive jaundice. The endoscopic } \\
\text { retrograde cholangiopancreatography procedure enabled definitive treatment without the need for surgery in the } \\
\text { remaining two patients. Two patients with fascioliasis underwent endoscopic retrograde cholangiopancreatography } \\
\text { due to clinical presentation of cholangitis, cholecystitis, and obstructive jaundice, leading to presumptive diagnosis } \\
\text { of cholangiocarcinoma. However, the final diagnosis was made using endoscopic retrograde cholangiopancrea- } \\
\text { tography following inspection of flat, leaf-shaped, motile flukes extracted from the bile duct. In one patient with } \\
\text { ascariasis, a longitudinal tubular structure was identified in the bile duct; emergency surgery was required. }\end{array}$ \\
\hline & $\begin{array}{l}\text { Conclusion: The diagnosis of parasitic diseases is clinically challenging, and definitive diagnosis requires endoscopic } \\
\text { retrograde cholangiopancreatography in some cases. Moreover, endoscopic retrograde cholangiopancreatography } \\
\text { provides a therapeutic option for ascariasis, fascioliasis, and some forms of hydatidosis. Accordingly, the use of }\end{array}$ \\
\hline $\begin{array}{l}\text { Cite this paper as: } \\
\text { Yılmaz S, Akıı M, Şimşek }\end{array}$ & $\begin{array}{l}\text { endoscopic retrograde cholangiopancreatography may change preoperative management and treatment strategies } \\
\text { for biliary system parasite infections. }\end{array}$ \\
\hline $\begin{array}{l}\text { M, Okur N, Erşen 0, Tuncer } \\
\text { AA. Endoscopic retrograde }\end{array}$ & Keywords: Echinococcosis, endoscopic retrograde cholangiopancreatography, Fasciola hepatica, biliary system \\
\hline
\end{tabular}

AA. Endoscopic retrograde cholangiopancreatography for biliary system parasites. Turk J Surg 2018; 34(4): 306-310.

'Department of General Surgery, Afyon Kocatepe University School of Medicine, Afyonkarahisar, Turkey 2Department of Microbiology, Afyon Kocatepe University School of Medicine, Afyonkarahisar, Turkey

${ }^{3}$ Clinic of Radiology, Afyon State Hospital, Afyonkarahisar, Turkey ${ }^{4}$ Department of Pediatric Surgery, Afyon Kocatepe University School of Medicine, Afyonkarahisar, Turkey

\section{Corresponding Author} Ahmet Ali Tuncer e-mail:drtaali@yahoo.com

Received: 10.01.2017 Accepted: 18.04.2017 Available Online Date: 03.01.2018

\section{oCopyright 2018} by Turkish Surgical Association www.turkisurg.

\section{INTRODUCTION}

Parasites are endemic in various regions of the world and are associated with severe health problems in these areas. Poor sanitation, overpopulation, intercontinental migration, and the international food trade contribute to the increasing prevalence of parasite infestations. As a result, parasitic infections are increasingly being recognized as a clinical problem, even in non-endemic countries. The involvement of the biliary system in parasitic infections may cause severe morbidity and, rarely, mortality due directly to the parasites or to related complications, even in childhood $(1,2)$. The clinical presentation of parasite infection varies depending on the type and location of infestation within the biliary tree. Hepato-biliary problems arise from compression of the biliary system by parasites or infestation of the bile ducts (3-5). Biliary infestation occurs due to the rupture of parasites into the biliary tree or direct transmission of parasites through the papillary orifice. These complications may result in obstructive jaundice or acute cholangitis, necessitating urgent decompression by surgical, radiological, or endoscopic techniques.

The diagnosis of biliary system parasites is challenging with conventional radiological methods. Although computed tomography and ultrasonography can successfully demonstrate the location of cysts within the liver, these techniques typically fail to demonstrate biliary tree involvement. Additionally, some parasite species (e.g., Fasciola hepatica) may mimic radiological features of cholangiocarcinoma. Accordingly, endoscopic retrograde cholangiopancreatography (ERCP) may play a role in the differential diagnosis and subsequent surgical treatment of suspected cases. ERCP provides a wide range of clinical benefits for biliary complications during both the pre- and postoperative periods (6). Although ERCP is commonly used for in patients with bile duct injury following hepatobiliary surgery, patients with parasite-related cholangitis or obstructive jaundice may also benefit from decompression of parasitic obstruction by $\operatorname{ERCP}(7,8)$. Moreover, endoscopic sphincterotomy $(\mathrm{ES})$ may be useful in the clearance 
of parasites from the bile duct and associated structures. ERCP may also aid in the closure of biliary fistulae during the postoperative period by decreasing intraluminal pressure within the biliary system (9).

The utility of ERCP in the treatment of biliary system parasites differs according to parasite type and intervention timing. For example, parasite extraction provides a therapeutic option for F. hepatica if antimicrobial therapy fails to completely eradicate biliary system parasites (10-14). Moreover, ERCP provides a bridge to safe surgery for Echinococcus granulosus by extracting vesicles from the biliary channel preoperatively. Additionally, ERCP and sphincterotomy have clinical benefits by decreasing the postoperative output of biliary fistulae occurring after surgery for E. granulosus.

Investigators performed 3,450 ERCP procedures over an eightyear period and encountered 22 cases of biliary system parasites ( $\mathrm{n}=19$ for $E$. granulosus, $\mathrm{n}=2$ for $F$. hepatica, and $\mathrm{n}=1$ for Ascaris lumbricoides). The aim of the present study was to determine clinical and radiological differences between biliary system parasite types. The role of ERCP in the diagnosis and management of biliary system parasites was also examined.

\section{MATERIAL AND METHODS}

The present retrospective study includes 22 patients with biliary system parasite infections identified from a total of 3,450 ERCP procedures performed during an eight-year period. Of these, E. granulosus infection was observed in 19 cases, F. hepatica in two cases, and A. lumbricoides in one case. The demographic and clinical features of the patients are depicted in Table 1. For patients with hepatic hydatid disease, the necessity of the ERCP procedure was determined according to the following criteria:

a. Preoperative ERCP was performed in cases of obstructive jaundice resulting from occlusion of the bile duct with hydatid membranes/fragments and/or daughter cysts in cases of hydatid cysts confirmed by radiological, serological, and blood tests.

b. Postoperative ERCP was performed in patients with external biliary fistulae following cyst surgery, new onset cholangitis, obstructive jaundice, or postoperative biloma (after percutaneous catheterization with a permanent fistula).

As the presentations of $F$. hepatica and A. lumbricoides infections have vague clinical and imaging findings, the decision to perform ERCP was made according to standard indications for ERCP. Endoscopic and additional surgical procedures were performed by S.Y. and M.A. using video duodenoscopy (EPX4400 HD Video GI Endoscopy System; Fujinon GmbH, Willich, Germany) with patients in the prone position. During ERCP procedures, all patients received fentanyl and midazolam intravenously, with additional doses provided as required to maintain sedation. Antibiotic prophylaxis was provided via intravenous administration of $1 \mathrm{~g}$ cefazolin. Duodenal peristalsis was reduced by intravenous hyoscine-N-butylbromide injection. For patients in the 1/a group, appropriate surgical procedures were performed according to ERCP and radiological findings. ERCP procedures are diagnostic only in patients with A. lumbricoides due to the inability to extract the parasites; therefore, open surgery, including choledochotomy and parasite extraction, is performed in such cases. Statistical Package for the Social Sciences 16.0 software for Windows (SPSS Inc; Chicago, IL, USA) was used to statistically evaluate the data. Numerical values were expressed as average or median values. Ethics committee approval was received according to the Declaration of Helsinki and Good Clinical Practice Guidelines. Written informed consent was obtained from the patients for the publication of this report and the accompanying images.

\section{RESULTS}

Investigators performed 3450 ERCP procedures between 2008 and 2016 at our center. Of these, 22 patients were found to have biliary system parasite infections during the ERCP procedure, with 19 cases of E. granulosus, two cases of $F$. hepatica, and one case of $A$. lumbricoides.

\section{E. granulosus}

Fifteen patients with liver hydatid cysts underwent ERCP preoperatively due to obstructive jaundice and cholangitis resulting from bile duct occlusion (Figure 1). Germinative membrane fragments, daughter cysts, and accompanying biliary sludge were causative factors extracted from the choledochus (Figure 2). Patients were scheduled for surgery after their liver function tests had returned to normal. Ten patients were referred to the original referring centers, whereas five patients underwent surgical interventions at our center; three patients underwent surgery via a laparoscopic approach, and the other two patients underwent surgery via laparotomy. No cases of postoperative mortality were observed, and patients were discharged with prescriptions for albendazole and annual control.

Four patients underwent ERCP following surgery performed 7 to 20 days previously at other centers due to persistently high output from biliary fistulae. Causative factors were germina-

Table 1. Demographic and clinical features of patients who underwent endoscopic retrograde cholangiopancreatography for the treatment of biliary system parasites

\begin{tabular}{|c|c|c|c|c|c|}
\hline Parasite & Age & Gender (F/M) & Timing $^{\dagger}$ & Surgery after ERCP & Definitive treatment \\
\hline Hydatidosis (19) & 52.6 & $7 / 12$ & $15 / 4$ & 13 & 2 \\
\hline Fascioliasis (2) & 71.0 & $1 / 1$ & $2 / 0$ & 1 & 1 \\
\hline Ascariasis (1) & 79.0 & $0 / 1$ & $1 / 0$ & 1 & 0 \\
\hline
\end{tabular}

ERCP: endoscopic retrograde cholangiopancreatography

'Timing: whether ERCP was performed preoperatively or postoperatively (preoperative/postoperative)

'Definitive treatment: whether ERCP provided definitive treatment, obviating the need for further surgery 
tive membrane fragments; an accompanying bile duct stone was observed in one patient. Two patients received temporary biliary stents in addition to sphincterotomy.

\section{F. hepatica}

Two patients with fascioliasis underwent ERCP due to the presence of cholangitis, cholecystitis, and obstructive jaundice informing a presumptive diagnosis of cholangiocarcinoma (Figure 3). However, the final diagnosis was made by ERCP following inspection of flat, leaf-shaped, motile flukes extracted from the bile duct (Figure 4). Indirect hemagglutination tests for fascioliasis were high, with a measured titre of $1 / 320$. As both patients had cholelitiasis, open cholecystectomy was performed, and both patients were discharged with prescriptions for triclabendazole.

\section{A. lumbricoides}

One patient was found to be infected with $A$. lumbricoides. He was referred to our center for ERCP with a diagnosis of suppurative cholangitis. As radiological and laboratory findings were strongly suggestive of suppurative cholangitis, the patient was scheduled to undergo ERCP. Although a longitudinal tubular structure was found in the bile duct, extraction through the papillary orifice was not possible for technical reasons. Emergency surgery was accordingly planned. Intraoperatively,

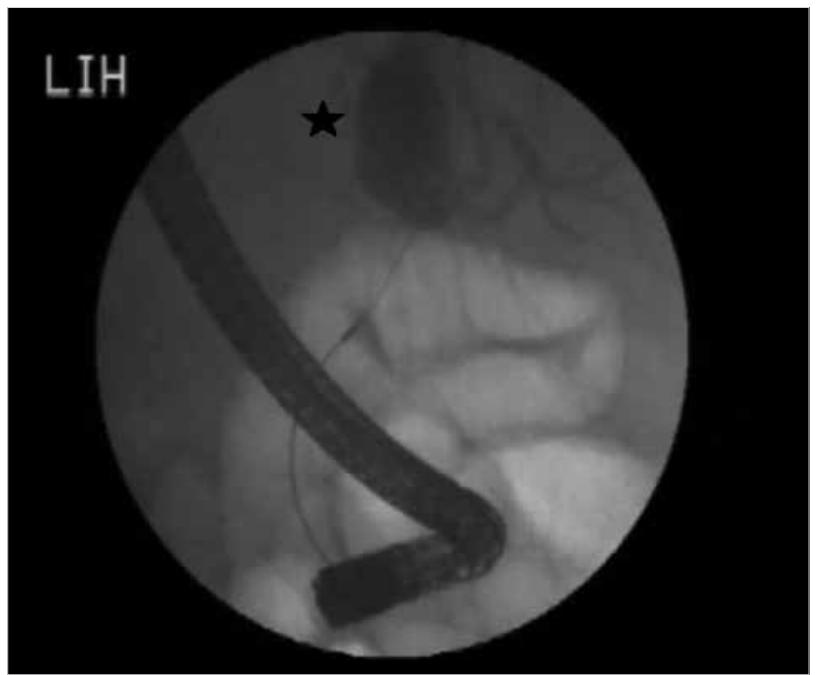

Figure 1. Cyst pouch of Echinococcus granulosus on cholangiography

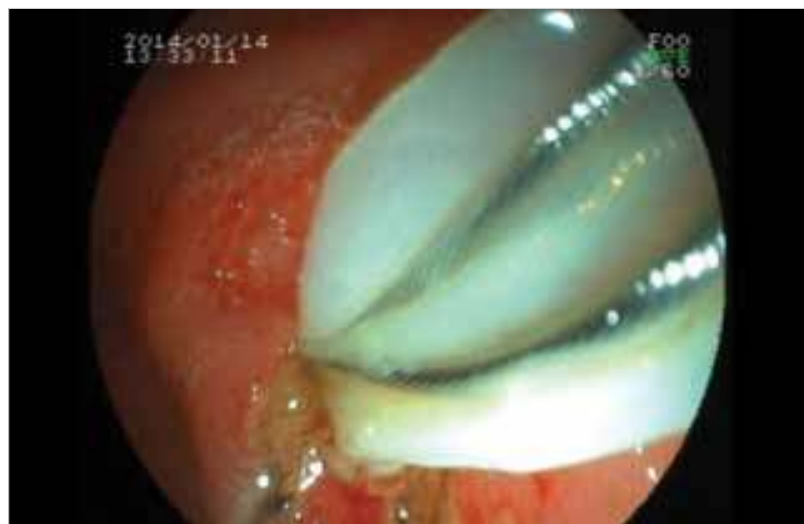

Figure 2. Germinative membrane extraction using a basket catheter severely infected bile, pus formation, and a 30-cm-long worm located in the lumen were observed (Figure 5). The procedure was completed with placement of a T-tube; however, the patient subsequently died despite intense supportive treatment.

\section{DISCUSSION}

Endoscopic retrograde cholangiopancreatography is an effective and reliable method for the treatment and differential diagnosis of various parasitic diseases involving the biliary system. Of these, the daughter vesicles and/or germinative membranes of $E$. granulosus are the most frequent cause of

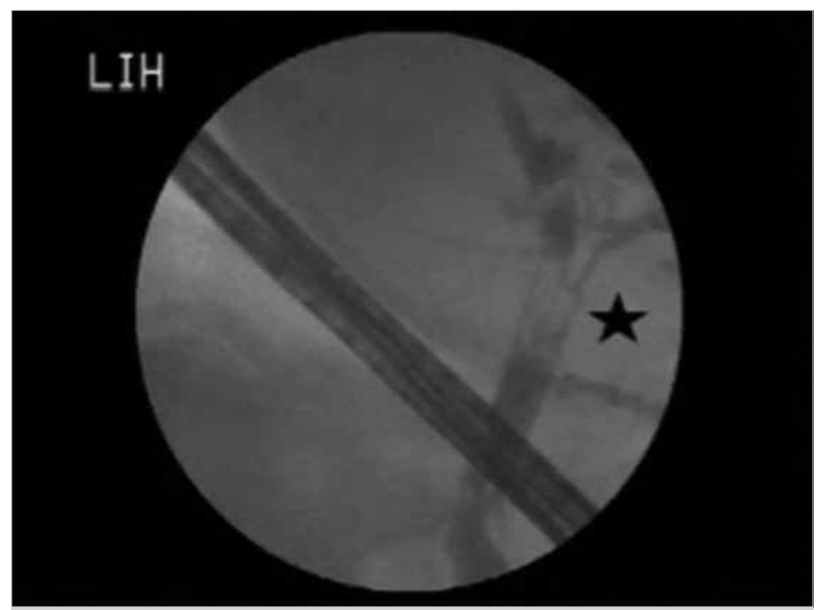

Figure 3. Irregular filling defect mimicking cholangiocarcinoma on cholangiography

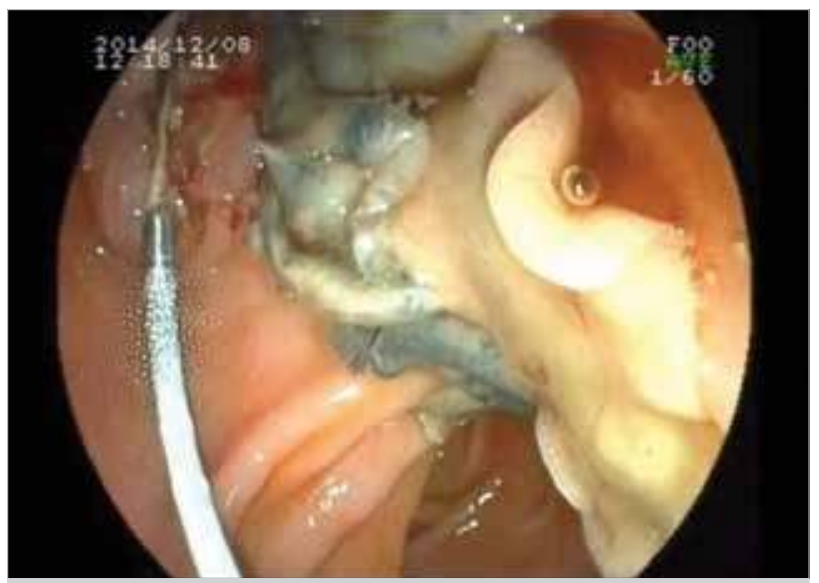

Figure 4. Extraction of Fasciola hepatica using a balloon catheter

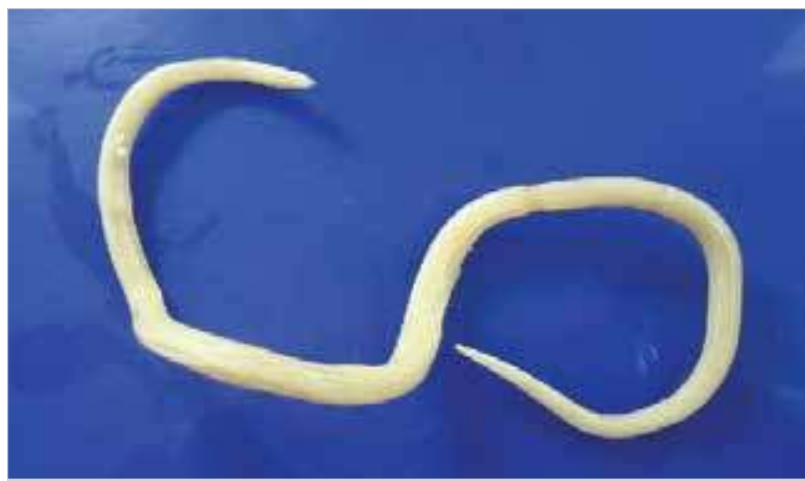

Figure 5. Ascaris lumbricoides extraction from the bile duct during emergency laparotomy 
biliary system conditions, such as jaundice, cholangitis, and biliary fistulae. Intrabiliary rupture is the most common and serious complication in patients with hydatid cysts (6). In particular, open and wide communication between the cyst wall and the biliary system may present as biliary colic, jaundice, cholangitis, or an abscess; it also rarely presents as anaphylaxis or pancreatitis (5). These patients may require ERCP during the preoperative period due to the aforementioned complications or during the postoperative period due to sustained biliary fistulae. In certain cases, wide communication between the cyst and biliary channel allows the germinative membrane and cyst contents to be completely evacuated during ERCP; further surgery may not be required.

In the present study, 15 patients underwent ERCP prior to surgery. Of these, further surgery was not required in two patients following cyst extraction and clearance of the biliary channel of daughter cysts and vesicles. Several previous studies have reported that up to $25 \%$ of patients can be cured without the need for further surgical intervention after preoperative ERCP (6). The postoperative complications observed after surgery for hydatid disease are persistent biliary fistulae, obstructive jaundice, and related biochemical abnormalities. ERCP plays a principal role in the management of these complications. Although daily fistula output, progression, and accompanying abscess formation determine the indications for ERCP, Adas et al. (15) recommended that the ERCP procedure should be performed at an early period. ES and/or stent placement are useful in the treatment of these complications. Four patients in the present study underwent ERCP due to persistent biliary fistulae; ES was successfully performed in two patients, and ES plus stent placement was successfully performed in the other two patients.

Fascioliasis is a parasitic disease that has acute (hepatic) and chronic (biliary) phases. Although it is a substantial clinical issue in developing countries, the incidence of fascioliasis is gradually increasing worldwide (13). The natural environment of the parasite is the duodenal lumen; it is transmitted to the liver parenchyma and biliary channel by an ascending route through the peritoneal cavity. The diagnosis of fascioliasis is often delayed due to non-specific radiological and clinical findings. Patients infected with F. hepatica are typically admitted with symptoms of biliary colic, liver abscess, choledocholithiasis, pancreatitis, and compressive symptoms mimicking cholangiocarcinoma $(11,12,14)$. ERCP can be performed for the differential diagnosis and definitive treatment of $F$. hepatica, thus avoiding further surgery (16). Two patients in the present study were admitted to our center with presumptive diagnoses of cholangitis and cholangiocarcinoma. Therefore, we performed diagnostic ERCP on these patients; final diagnosis and eventual treatment were enabled by the procedure. $A$ single dose of triclabendazole was also administered to these patients.

The adult forms of $A$. lumbricoides inhabit the duodenal lumen and are rarely transmitted to the biliary channel by penetrating the papillary orifice. Once it has entered into the choledochus, A. lumbricoides causes severe cholangitis, obstructive jaundice, acalculous cholecystitis, and, rarely, pancreatitis. Because albendazole treatment is ineffective in the treatment of biliary ascariasis, parasites should be directly removed from the bile duct (17). Endoscopic procedures should be initially attempted to remove parasites, as laparotomy may increase mortality and aggravate sepsis in patients with cholangitis (18). However, it may be impossible to extract parasites due to their size; in these cases, laparotomy is necessary. In the present case, although we performed ERCP as the initial procedure, it was impossible to remove the parasite for technical reasons; therefore, choledochotomy, parasite removal, and Ttube placement were performed.

\section{CONCLUSION}

Although parasites are a rare cause of cholangitis, they may cause severe morbidity and even death in certain cases. The diagnosis of parasitic disease is challenging with standard imaging modalities if the parasite is located within the biliary system. Accordingly, definitive diagnosis may only be possible with ERCP in some cases. Moreover, ERCP provides a therapeutic option for ascariasis, fascioliasis, and some forms of hydatidosis. Accordingly, the use of ERCP may change the preoperative management and treatment of biliary system parasites.

Ethics Committee Approval: Ethics committee approval was received for this study from the ethics committee of of Afyon Kocatepe University.

Informed Consent: Written informed consent was obtained from patients who participated in this study.

Peer-review: Externally peer-reviewed.

Author Contributions: Concept - S.Y., M.A., A.A.T., O.E.; Design - S.Y., M.A., M.Ş.; Supervision - S.Y., M.A., A.A.T., N.O.; Resource - S.Y., M.A., M.Ş. N.O.; Materials - O.E., M.A., M.Ş.; Data Collection and/or Processing N.O., S.Y., O.E.; Analysis and/or Interpretation - M.A., S.Y., O.E.; Literature Search - A.A.T., N.O., S.Y.; Writing Manuscript - A.A.T., M.A., S.Y.; Critical Reviews - A.A.T., M.A., S.Y., O.E., N.O., M.Ş.

Conflict of Interest: The authors have no conflicts of interest to declare.

Financial Disclosure: The authors declared that this study has received no financial support.

\section{REFERENCES}

1. Tuncer AA, Embleton DB, Yilmaz S, Okur N, Kacar E, Bayraktaroglu A. ERCP treatment for intrabiliary rupture of hepatic hydatid cyst in a child. J Exp Clin Med 2016; 33: 37-39.

2. Miman O, Okur N, Cufali D, Yilmaz S. Suppurative cholangitis caused by ascaris lumbricoides: Report of a fatal case. Kafkas Univ Vet Fak Derg 2012; 18: 235-237.

3. Akaydin M, Erozgen F, Ersoy YE, Birol S, Kaplan R. Treatment of hepatic hydatid disease complications using endoscopic retrograde cholangiopancreatography procedures. Can J Surg 2012; 55: 244-248. [CrossRef]

4. Yücesoy AN, Poçan S. Secondary gallbladder hydatidosis and nonfragmanted germinative membrane sourced obstructive jaundice caused by intrabiliary ruptured hepatic hydatid cyst (a case report): two rare complication of the intrabiliary ruptured hepatic hydatid cyst. Hepatobiliary Surg Nutr 2014; 3: 209-211.

5. Bayhan Z, Yilmaz S, Tiryaki C, Kargi E, Ucar BI. Acute Pancreatitis due to rupture of the hydatid cyst into the biliary tract: a case report. Natl J Med Res 2014; 4: 92-94. 
6. Dolay K, Akbulut S. Role of endoscopic retrograde cholangiopancreatography in the management of hepatic hydatid disease. World J Gastroenterol 2014; 20: 15253-15261. [CrossRef]

7. Yilmaz S, Ersen O, Ozkececi T, Turel KS, Kokulu S, Kacar E, et al. Results of the open surgery after endoscopic basket impaction during ERCP procedure. World J Gastrointest Surg 2015; 7: 15-20. [CrossRef]

8. Yilmaz S, Akici M, Okur N, Türel S, Erşen O, Şahin E. Spontaneous postoperative choledochoduodenal fistula due to bile duct injury following laparoscopic cholecystectomy. Int J Surg Case Rep 2016; 25: 199-202. [CrossRef]

9. Ambregna $S$, Koch $S$, Sulz MC, Grüner B, Öztürk $S$, Chevaux JB, et al. A European survey of perendoscopic treatment of biliary complications in patients with alveolar echinococcosis. Expert Rev Anti Infect Ther 2017; 15: 79-88. [CrossRef]

10. Ozer B, Serin E, Gümürdülü Y, Gür G, Yilmaz U, Boyacioğlu S. Endoscopic extraction of living fasciola hepatica: case report and literature review. Turk J Gastroenterol 2003; 14: 74-77.

11. Jha AK, Goenka MK, Goenka U, Chakrabarti A. Hepatobiliary fascioliasis in non-endemic zones: a surprise diagnosis. Arab J Gastroenterol 2013; 14: 29-30. [CrossRef]

12. Kang BK, Jung BK, Lee YS, Hwang IK, Lim H, Cho J, et al. A case of Fasciola hepatica infection mimicking cholangiocarcinoma and
ITS-1 sequencing of the worm. Korean J Parasitol 2014; 52: 193196. [CrossRef]

13. Yilmaz S, Celep B, Altindis M, Arikan Y. A stranger in the main bile duct. Fasciola hepatica, the extraction by ERCP. Selcuk Tıp Derg 2014; 30: 172-174.

14. Sezgin O, Altintaş E, Tombak A, Uçbılek E. Fasciola hepatica-induced acute pancreatitis: report of two cases and review of the literature. Turk J Gastroenterol 2010; 21: 183-187. [CrossRef]

15. Adas G, Arikan S, Gurbuz E, Karahan S, Eryasar B, Karatepe O, et al. Comparison of endoscopic therapeutic modalities for postoperative biliary fistula of liver hydatid cyst: a retrospective multicentric study. Surg Laparosc Endosc Percutan Tech 2010; 20: 223-237. [CrossRef]

16. Okudan M, Egeli T, Taşkesen F, Yılmaz Ş. A rare cause of obstructive jaundice: Fasciola hepatica. Turk J Surg 2011; 27: 164-166. [CrossRef]

17. Mitoro A, Yoshikawa M, Yamao J, Yoshida M, Kojima K, Sawai M, et al. Endoscopic extraction of biliary ascariasis by using a wireguided basket, without a sphincterotomy. Gastrointest Endosc 2007; 65: 327. [CrossRef]

18. Lee YS, Kim DK, Choi YH, Kim DJ, Shim MS, Shim CS, et al. Biliary ascariasis as a cause of acute cholangitis: a case report. Pancreatology 2013; 13: 23-24. [CrossRef] 